\title{
Protection or pleasure: female footwear
}

\author{
Mariana Seferin ${ }^{\mathrm{a}^{*}}$ and Júlio van der Linden ${ }^{\mathrm{a}, \mathrm{b}}$ \\ ${ }^{a}$ Programa de Pós-Graduação em Design, Federal University of Rio Grande do Sul, Porto Alegre - RS, Brazil \\ ${ }^{\mathrm{b}}$ Departamento de Design e Expressão Gráfica, Federal University of Rio Grande do Sul, Av. Osvaldo Aranha, \\ 99 - $4^{\circ}$ andar- sala 408, CEP 90035-190 - Porto Alegre, RS, Brazil.
}

\begin{abstract}
This article addresses the love for shoes by the perspective of design and emotion. Reviewing the footwear history, we realize that it did not take too long for the shoes start to have new functions, aesthetic and symbolic, which eventually came to have greater relevance in the acquisition of women's shoes. Today, these outweigh the importance of physical comfort for many women, that once feeling pretty, do not realize the discomfort of the shoe. Studies indicate that the objects we love have a strong influence on our sense of identity, especially when dealing with clothing articles that have the power to show on our appearance our identity, tastes and preferences. Crossing the semiotics field, the footwear is analyzed as an object of feminine desire, imbued with symbolic relations. As a result, we propose a framework to describe the emotional relationship between women and shoes.
\end{abstract}

Keywords: female footwear, design and emotion, love for products, protection, pleasure.

\section{Introduction}

The use of footwear dates back to the protection of the feet in the prehistoric period, but history shows that it was not long before it served new functions, aesthetic and symbolic. Today, they outweigh the importance of physical comfort for many women who, while feeling pretty, do not realize the discomfort of the shoe. To the extent that its use is part of a social code, adopted to some extent in a voluntary manner, the initiatives to raise awareness about the risks run into barriers [1].

Many studies warn about the negative effects of high heels. Aghazadeh and Lu [2] demonstrated that its use affects the ability to lift loads. Nagata [3] relates them to accidents on stairs. Lee et al. [4] affirms that high heels may lead to greater muscular effort, causing discomfort and fatigue. The use of harmful footwear is linked to symbolic values, which transform them into elements of social obligation and fetish. Thus, women pay a high price in exchange for their personal success [5], using the shoes as a symbol of power and elegance [6] and even exploring the association of fetish with power [7].
The emerging of the shoe was due to great need to protect the feet from cold and soil. His initial appearance was that of a bag tied at the bottom, with the time was developing the other constituent parts of a shoe, sole, insole, the upper. Looking at the history of footwear, it is clear that from its inception was not privileged comfort. Initially, the difficulties related to comfort were related with the available materials and with the lack of knowledge of anatomy, biomechanics and physiology. More recently, the scientific and technological developments enabled the design and manufacture of shoes to offer high levels of comfort and safety.

Despite the advances that allow us to wear more comfortable footwear, today, women still submit themselves to physical discomfort in favor of feeling elegant, beautiful and / or sexy, and thus feeling comfortable psychologically. We often hear women saying that they do not feel pain or discomfort when using high heels and pointed toes shoes, maybe the pain it is annulled by the psychological comfort. Therefore, one can say that for those women who prefer the elegance rather the comfort, what really matters in the choice of footwear would be the formal and aesthetic aspects, which comes to refer the

${ }^{*}$ Corresponding author E-mail: marianaseferin@gmail.com 
affection with the use of products, the Design and Emotion.

As a consequence of intensifying the use of highheeled shoes, has been growing concern about its effects on health. Many studies, prove the adverse effects of the use of women's footwear designed from stylistic criteria, such as high heels and pointed toes [8,2,9-14]. However, despite all the knowledge developed in the recent decades by the areas of Biomechanics, Physiology and Ergonomics, fashion factors still determinate the shoe design, especially the female footwear and its adoption by the women is related with several factors $[15,12]$. There is evidence that factors as the appearance importance and the attitude toward in general risks are crucial for the comfort and risk appraisal process in the use of fine high-heeled shoes with thin nozzles [16].

The conflict between the objectivity of the recommendations from the areas related to health and safety and risk behavior adopted by women who use high heels (and fine nozzles) can be explained from the supremacy of the symbolic benefits to the detriment of physical risks. Therefore, this article focuses on the emotional relationship with female footwear and proposes a framework of its description.

\section{Method}

This work was developed based on literature review, considering the following themes: risks in the use of high heels, fashion, semiotics, emotions and love for products. Based on theoretical analysis, we created a proposed framework of the affective relationship with feminine footwear.

\section{The basis for the framework}

Universally, the high-heeled shoe is seen as a fetish; for the semiotics, the shoe is seen as a symbol of power. This can be understood by analyzing the history, mythology and fairy tales. At many times the shoe served to differentiate social classes. At first for separating the barefoot from the people that wore shoes and then differentiating the classes according to the different shoe styles, giving to the user the power of a particular footwear style, being this power related to social prestige or associated with purchasing power. In fairy tales and mythology, the shoes are often associated with power and magic [6].
It is a common association of high-heeled shoes as a symbol of elegance and sensuality. This perception of high-heeled shoes as stylish is also part of the historical past, where the high heel was initially intended for those with a higher purchasing power. Thus it was also seen as a symbol of nobility, the greater the heel, the higher was the social position of the individual [6].

In the book Emotional Design, Donald Norman [17] reports that humans have three levels of brain structure, they are the visceral, behavioral and reflective level. These levels can be translated into product characteristics, as follows: the visceral, the appearance of the product, its formal characteristics; the behavioral, the pleasure (physical sensation) and the use effectiveness; and the reflective level, affirming the self-image, the personal satisfaction and the user memories (prestige, rarity and exclusivity perception).

According to Ahuvia [18], "the people, and things, we love have a strong influence on our sense of who we are, on our self." Loved objects represent and influence our sense of personal identity. This can be seen specially in apparel and personal use products. For Belk [19] people use their favorite objects to enlarge, expand and fortify their sense of self.

Our personal objects, besides exposing our identity, also exalt our personal tastes and preferences. To Kälviäinen [20] the taste should be interpreted by the designer as a demonstration of lifestyle preference and as products orientation. The taste is intimately connected with the expression of identity and social interaction.

It is well known that humans have affection for products and this affection can be expressed by feelings and emotions. "Affect has been described as part of 'the consumer's psychological response to the semiotic content of the product" [21].

The relationship of people and industrial products has been approached more recently from the perspective of affection. Desmet and Hekkert [22] "describes the various ways in which products can act as emotional stimuli". Norman [17] states that "emotions reflect our personal experiences, memories and associations". Ahuvia [18] states that objects that we love have a strong influence on our sense of identity. Russo [23] argues that "people tend to describe their love for a product as something that is dynamic and endures over time".

According to Desmet and Hekkert [24] there are three types of product experience: aesthetic experience, which is linked to our product perception, as the touch, the smell, the visual, "the beauty one experiences when physically interacting with a 
riences when physically interacting with a product"; the next is experience of meaning, associated with memories and meanings which the person relates to the product and in this way "assign personality or other expressive characteristics"; the last one is the emotional experience, that relates to the emotions and feelings resulted by the evaluation that people make of a product.

Beatriz Russo in her doctoral thesis discusses the love of products, highlighting the love for cars (men and women) and shoes (women) [23]. In her research she discusses the love that came with the time of use and do not approach the "love at first sight" that motivates the purchase. It was collected 50 reports of different participants who described their love for specific products. These reports show that the love felt for products is rewarding, a long lasting relationship which is derived from a dynamic experience where there are affective experiences that arise from this significant relationship causing wellbeing to the people. Thus, Russo says that is because of these rewards occasioned by the love felt for products that make people seek to extend the life of these special products. She also points out ways to design researchers and product developers to promote in their research and projects rewarding experiences and enduring relationship between people and products.

The effect of emotions in relation to female shoes with thin high heels and pointed toes, considering the comfort and risk perception of women has been investigated by van der Linden [16]. The results indicate that the "perception of comfort and perception of risk are influenced by individual characteristics, which were identified as dominant references" [16]. The reference is dominant according to the person orientation. People who have a dominant orientation as a reference to pleasure, favor the appearance that changes their perception of comfort, so the risk is denied. But people who have pain as a dominant reference, neglect their appearance and have a great sense of risk perception that affects their perception of comfort.

The framework proposed by van der Linden [16] includes the product dimensions for consumer needs (appearance, usability and functionality), the stimuli forms developed by Desmet and Hekkert (object, agent or event), the dominant reference (pursuit of pleasure or avoidance of pain), the processing levels developed by Norman that determine the evaluation (visceral, behavioral or reflective) and the affective responses (pleasant emotions, feelings of indifference and / or unpleasant emotions). The idea of dominant reference allow to understand the different ways a product can be perceive as taking into account the way how happens the stimulus, "the same footwear can be considered sexy (as object), dangerous (as an agent of an accident) and elegant (suitable for use in events that require good presentation" [16].

\section{The framework}

Fetish, elegance, comfort, identity, love, are words associated with the experience of the use or possession of women's shoes. More than protection, the original purpose, the aesthetic and symbolic aspects dominate the manufacturers, the media and consumers discourse. Only the comfort maintains its functional attribute, the footwear goal. But, as discussed in van der Linden [16], the perception of comfort is not carried out in an objective, rational way, but in a subjective way, mediated by emotions. Among these, the love, approached by Russo [23], plays an important role in the interaction between women and shoes.

This begs the question: What kind of love do women feel for shoes, which makes them take risks? Based on the literature and as a research hypothesis, this paper proposes that there are two different kinds of love: Love for Shoes and Love by the Shoe (Figure 1). The first expressed by women that are influenced by fashion trends, seek to have lots of pairs of shoes, do not bother with physical discomfort. Many have a fetish for shoes and they value brands and designers. Their goal is to obtain social status and they feel that if they are not wearing the latest trend they will be seen as socially inferior within their social ranks and classes. Here the shoe is seen as a symbol of power, which will influence the social status and affirming their social identity. The second refers to emotionally gratifying memories experienced with that particular shoe. Here the comfort and personal symbolism often has greater relevance than simply the aesthetics. The shoe is seen as part of the user identity, who has developed a sense of attachment and oneness with it, which can generate a special attention with regard to the preservation of footwear and a quest for extending the life of it. 


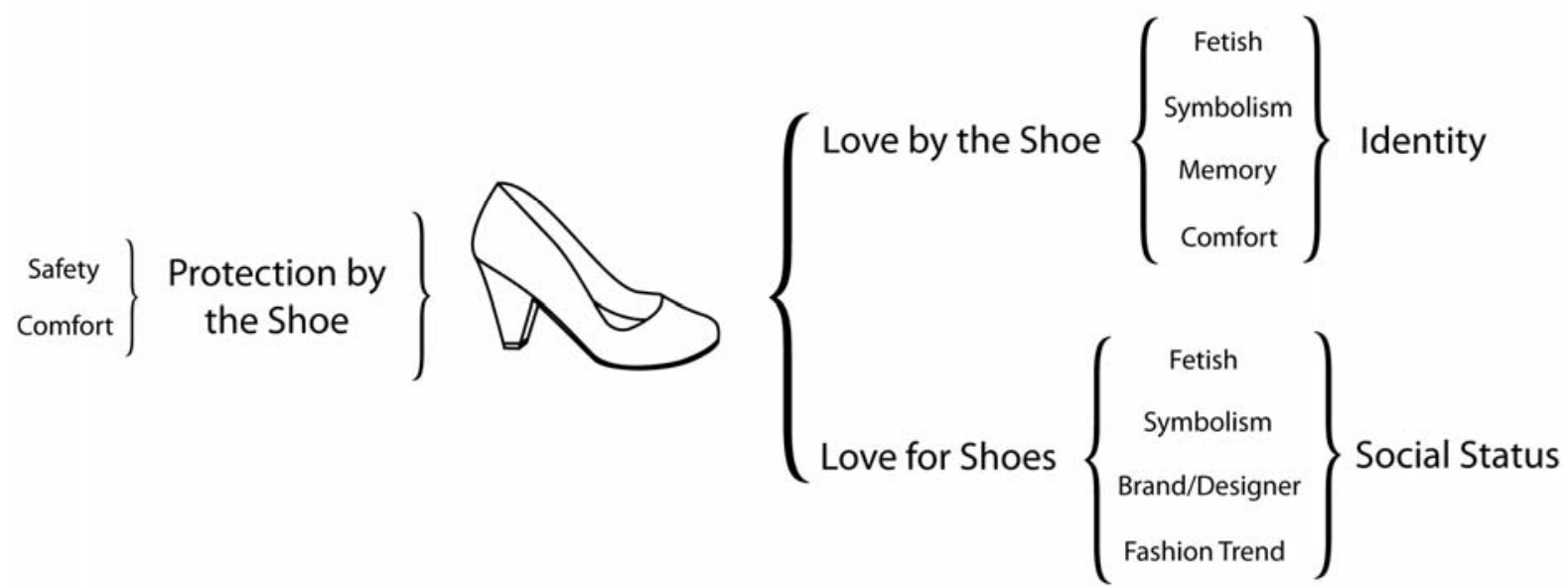

Figure 1 Female Footwear-Relationship Framework

Besides the two cases of affective relationship with shoes, there would still be a relationship in which not have established emotional ties, but only practical in nature. This case, as opposed to others, would be the Protection by the Shoe. Here, the footwear is seen as an item of protection for feet, what matters is the safety and comfort offered by the footwear.

It is possible to associate these three categories to Norman's three levels of brain processing, where the Love for Shoes would be at the visceral level, which is responsible for quick judgments, attraction and where the physical characteristics prevail. Love by the Shoe is in the reflexive level, which is contemplative, sophisticated, comes to the perceived rarity, experience, exclusivity, self-image and about the messages that a product sends to people. And, the Protection by the Shoe is located at the behavioral level, where appearance does not matter as much as the product performance and usability.

This research assumes that there are possible crossings between the Love for Shoes, Love by the Shoe and Protection by the Shoe, and with these crossings profiles of individuals can be created which indicate their preferences. These profiles can come to assist the development of new shoes that provide the attributes selected by those. As Norman [17] said the designer should know how are people for whom the product is intended.

\section{Conclusions}

The proposed framework aims to better describe the reality of the relationship between women and shoes. It presents an improvement compared to van der Linden's framework [16], by adding to the pleasure-pain axis, the possibility of different kinds of pleasure, such as the pleasure of ownership associated with affective memory (love by the shoe), and the pleasure of possession by following trends (love for shoes). This distinction theoretically corresponds to Norman's processing levels and also with Desmet and Hekkert's types of experience with products. By integrating complementary views, the framework provides greater sensibility to individual variations.

To the extent that it is a theoretical construct, the framework needs to be tested and validated. For this purpose, the continuity of this research will include the identification of women's groups that correspond to profiles that can be associated with the three types of proposed relationships between women and shoes. Based on this first study the formation of focus groups will be established which will comprise of women who have strong emotional ties with shoes, aiming to identify and test whether the dimensions included in the framework are valid to express the feeling that they have for the shoes, and to check if there are other motivations to love them. With the focus groups it's expected that the generation of knowledge will contribute in the development of a shoe design parameter. 


\section{References}

[1] Linder, M.; Saltzman, C. L. , 1998. A history of medical scientists on high heels. International Journal of Health Services, v. 28 , n. 2, p. 201-225

[2] F. Aghazadeh and H. Lu, Relationship between posture and lifting capacity, International Journal of Industrial Ergonomics, v. 13 (1994), pp. 353-356.

[3] H. Nagata, Rational index for assessing perceived difficulty while descending stairs with varius tread/rise combinations, Safety Science, v.21 (1995), 37-49.

[4] C. Lee, E. Jeong and A. Freivalds, Biomechanical effects of wearing high-heeled shoes, International Journal of Industrial Ergonomics, v. 28 (2001), pp. 321-325.

[5] E. O. Smith and W. S. Helms, Natural selection and high heels, Foot and Ankle International, v. 20, n. 1 (1999), pp. 55-57.

[6] M. Danesi, Of Cigarettes, High Heels, and Other Interesting Things: An Introduction to Semiotics, ed., Palgrave MacMillan, New York, 2008.

[7] V. Steele, Fetiche: moda, sexo \& poder, ed., Rocco, Rio de Janeiro, 1997.

[8] G. Gehlsen, J. Braatz and N. Assmann, Effects of heel height and knee rotation and gait, Human Movement Science, v. 5 (1986), pp. 149-155.

[9] D. P. Manning and C. Jones, High heels and polished floors: the ultimate challenge on slip-resistance, Safety Science, v. 19 (1995), pp. 19-29.

[10]H. B. Menz and S. R. Lord, Footwear and Postural Stability in Older People, Journal of the American Podiatric Medical Association, v. 89, n. 7 (1999), pp. 346-357.

[11]S. Arnadottir and V. S. Mercer, Effects of footwear on measurements of balance and gait in women between ages of 65 and 93 years, Physical Therapy, v. 80, n. 1 (2000), pp. 17-27.

[12] V. Monteiro, Ergonomia, Design e Conforto no Calçado Feminino. Masters Dissertation, Pontifícia Universidade Católica do Rio de Janeiro, Rio de Janeiro, 1999.

[13] A. Gefen, M. Megido-Ravid, Y. Itzchak and M. Arcan, Analysis of muscular fatigue and foot stability during high-heeled gait, Gait and Posture, v. 15 (2002), pp. 56-63.

[14]A. Karahan and N. Bayaraktar, Determination of the usage of body mechanics in clinical settings and the occurrence of low back pain in nurses, International Journal of Nurse Studies, v. 41, n. 1 (2004), pp. 67-75.

[15]K. S. Seale, Women and Their Shoes: Unrealistic Expectations? Foot and Ankle, v.44 (1995), pp. 379-384.

[16] J. C. S. van der Linden, A descriptive model of comfort and risk perception in women's shoes, Doctor of Engineering Dissertation, Federal University of Rio Grande do Sul, 2004.

[17]D. Norman, Emotional Design, ed., Basic Books, New York, 2004.

[18]A. C. Ahuvia, Beyond the Extended Self: Love objects and Consumers' Identity Narratives, Journal of Consumer Research, v. 32 (2005), pp. 171-184.

[19]R. W. Belk, Possessions and the Extended Self, Journal of Consumer Research, vol. 15 (1988), pp. 139-168.

[20] M. Kälviäinen, Product Design for Consumer Taste, in: W. S. Green and P. W. Jordan, Pleasure with Products: beyond usability, ed., Taylor \& Francis, London, 2002, pp. 77-95.

[21] N. Crilly, J. Moultrie and P. J. Clarkson, Seeing things: consumer response to the visual domain in product design, Design Studies 25, ed., Elseveier (2004), pp.547-577.

[22]P. M. A. Desmet and P. Hekkert, The Basis of Product Emotion, in: W. S. Green and P. W. Jordan, Pleasure with Products: beyond usability, ed., Taylor \& Francis, London, 2002, pp. 61-68.
[23]B. Russo, Shoes, cars and other love stories: investigating the experience of love for products, Doctoral thesis, Delft University, 2010.

[24]P. M. A. Desmet and P. Hekkert, Framework of Product Experience, International Journal of Design, 1 (2007), pp.57-66. 